the evidence and expert opinion to be found in the well-illustrated and excellent scientific memoir now under review indicate a more recent age for Pithecanthropus. It belongs, not to the Pliocene, but at the utmost to an early Pleistocene formation.

The late Prof. Emil Selenka, who did more than any man of his time to advance our knowledge of the higher primates, saw very clearly that the right way to solve the Pithecanthropoid problems was not discussion, but exploration. After his death in 1902, his widow took up the aim he had in view, and the manner in which she has carried it out commands our unstinted praise. Only those who have organised a scientific expedition know the care, labour, and expense entailed. Financial assistance was obtained from learned institutions in Berlin and Munich, but the major part of the expenditure had to be met from Fräu Selenka's private purse. Scientific investigators and overseers had to be selected and sent out; coolies had to be engaged-as many as seventy-five were employed at one time-and barracks built for them; Fräu Selenka accompanied the expedition into this remote and unhealthy part of Java. Extensive mining and digging operations were necessary for the fossilbearing layer lies under. 35 feet of a sedimentary deposit of volcanic origin. In the seasons $1907-8$ 10,000 cubic metres of material were removed, and forty-three large boxes filled with the fossil remains found. The contents of these boxes were sent to Europe and distributed amongst seventeen specialists. Their reports, with an introduction by Fräu Selenka and a summary of results by Prof. Max Blanckenhorn, make up the present memoir.

So far as Pithecanthropus itself is concerned, the expedition was a failure; the stone which Dubois erected to mark the spot of his discovery was found, but no further trace was seen of the much-discussed fossil primate. In the dry bed of a tributary of the Bengawan-about two miles from the scene of Dubois's discovery-the crovn of a human tooth was picked up; it is a human lower molar of rather remarkable dimensions, but otherwise showing no special feature beyond its state of preservation. Dr. Walkhoff found that the dentine within the enamel cap was replaced by a fossilised organic matrix. From its condition he infers that it may be older in point of time than the remains found of Pithecanthropus, and is inclined to regard it as the earliest known trace of man.

Dr. E. Carthaus has prepared cven a greater surprise for the readers of this memoir. In the same stratum as contained Pithecanthropus he has found traces of man's existence. These traces are:-(I) Certain splinters of bones and tusks; (2) hearth foundations and wood charcoal. $\mathrm{He}$ is quite aware of the fact that jungle fires by ignition from volcanic outbursts still occur in Java, but believes the appearances he has seen cannot be explained by any accidental conflagration.

On the slender evidence thus brought forward by Drs. Walkhoff and Carthaus, Fräu Selenka supports the theory that man was a contemporary of Pithecanthropus, and that therefore.the latter is an aberrant form, taking no place in the line of human evolution. The evidence, in our opinion, is rather of the nature of suspicion than of fact; the Selenka expedition leaves the problem of Pithecanthropus--so far as concerns its structure and position, unchanged, but it may be otherwise as concerns its geological age. Dr. E. Carthaus regards the Pithecanthropus stratum as belonging to a comparatively recent Pleistocene formation; Fräu H. Martin-Icke finds that 87 per cent. of the gasteropods found in it are modern forms, and concludes that the formation must be well within the NO. 2 I 76 , VOL. 87$]$
Pleistocene period; the evidence and opinion of the botanist, Dr. J. Schuster, tend to the same conclusion.

The problems relating to the estimation of the age of a fauna of a tropical and distant country are many and difficult; most palæontologists will follow the example of Dubois and look to the mammalian fauna as the means of fixing, if not the age, at least the degree of evolutionary change undergone by higher vertebrates in this part of the earth since the period of Pithecanthropus. It is the mammalian fauna which is best known; Dubois found remains of nineteen genera and twenty-seven species; Dr. H. Stremme and Dr. W. Jancnsch, who describe the mammalian remains of the Selenka expedition, found fourteen genera and seventeen species, many of which are new. The whole of the mammalian fauna contemporaneous with Pithecanthropus has been extinguished or modified, and hence those authorities lean towards Dubois's estimate that Pithecanthropus belongs to the Pliocene period which is at least not on a point of geological age that Pithecanthropus can be excluded from the genealogy of modern human races.

Prof. Blanckenhorn's general summary of the results of the expedition constitutes one of the best chapters of this memoir. He recognises the difficulty of drawing a line between Pliocene and Pleistocene in the formations of Europe and the even greater complexity in correlating the geological data of Europe and Java. As a tentative hypothesis he places the age of Pithecanthropus in the first interglacial period, corresponding to the formation of the Norfoll beds; the Heidelberg man-whose lower jaw only is known from the Mauer strata-he places in the second interglacial period, while the Neanderthal race he assigns to the third period. From an anatomist's point of view this provisional dating will answer very well, for these three forms are certainly progressive steps towards the modern human type.

A. KeIth.

\section{DR. G. JOHNSTONE STONEY, F.R.S.}

D. JOHNSTONE STONEY has passed away, one of the last of those who, during the latter half of the nineteenth century, contributed to the development of the modern ideas of the constitution of the atoms, which have borne such a rich harvest during the last two decades.

It is often difficult to get back to the point of view from which to estimate correctly the pioneer work of those who took the first steps; often the new ideas introduced by them have become the commonplace, so to speak, of science, but it is just these first steps breaking away from the older positions which mark the far-seeing intellect.

So early as $187 \mathrm{I}$ we find Stoney endeavouring to formulate a relation for spectral lines depending upon possible simple harmonic modes of vibration in the atom, and he succeeded in finding a numerical relationship of a simple character in the case of the hydrogen spectrum, which has proved to be the forerunner of much subsequent work. Twenty years later he returned to the subject in a paper in which he considered the question more systematically, viewing the internal movements of the atom as those of a planetary system. Much work had been done by others in the meantime in following up the clue which Stoney had found in the numerical relationships of the spectral lines of hydrogen, and he was able himself to show further that double and triple lines would be produced by perturbations of elliptic orbits described under controlling forces in the atom, double lines being attributed to apsidal motions, triple lines to precessional motions. These conceptions of the constitution of the atom afterwards found satisfactory 
support in Preston's observations on the Zeeman effect.

He took a keen interest in the development of the kinetic theory of gases, to which he made notable contributions. In 1867 he arrived at his estimate of the size of molecular dimensions, which is substantially that made by Kelvin a year or so later, and by Loschmidt two years previously.

By utilising his value of the mass of the atom Stoney was able to give, at the Belfast meeting of the British Association in 1874 , the first calculation of the atomic charge in electrolysis. To this quantity he gave the name electron, which is now very generally adopted, and has proved a most suitable term. It was to the orbital movements of the electrons in the atoms, to which, as we have seen, Stoney attributed in I89I the spectral lines and their various singularities.

Stoney invariably invented a nomenclature for the quantities he was dealing with, where none already existed. Such new terms are continually to be met with in his writings. Many of them have been found by others to be most convenient, and have consequently taken root in science, as, for example, his term wavelet, employed advantageously in his papers on microscopic vision, in connection with his method of resolution into plane wave fronts. This facility in suggesting suitable terms proved most useful when serving on the now famous committee of the British Association which devised our present system of electrical units, and of which he was one of the early members.

Stoney was the first to see that the movements in Crooke's radiometer were not due to radiation directly, but arose from unsymmetrical gaseous impacts resulting from unequal heating of the surfaces of the rotating vanes. His original explanation, however, required modification, afterwards supplied by Maxwell and Osborne Reynolds.

He introduced into cosmical physics considerations of a limit to each planet's power of retaining a gaseous envelope, which are of the highest interest in connection with the moon and with Martian questions. He showed that helium, as well as hydrogen, must eventually escape from the earth's atmosphere, a fact with important bearings on the past history of the radio-activity of the materials of the earth's crust.

Stoney's ideas were sometimes rather ahead of the recognised requirements of the day, and consequently paid the penalty of neglect which unfortunately sometimes happens in such cases; indeed, one of his papers on a periodic scheme of the elements, predicting, among other points, the atomic weights of the "inert" group, remained unpublished on the mistaken advice of one of the greatest of his contemporaries. This very scheme is now thought by many to be the most satisfactory of any yet devised.

He was essentially of a philosophic turn of mind, and wrote several papers on ontology and kindred subjects, but at the same time he took delight in all new developments of both industry and science, rejoicing that his span of life had coincided with what he considered would probably prove in the world's history to have been the period of most rapid advance, flowing from the first systematic application of scientific method on an extended scale to industrial progress. He would describe how as a child he had witnessed the first use of illuminating gas in the streets of Paris, and would with evident pleasure recount the many achievements of man in his time.

Stoney was born in King's Co., Ireland, in 1826 . His mother was a Blood of County Clare. His ancestry belongs to the Protestant settlers in Ireland of the sixteenth and seventeenth centuries, a class NO. 2 I. 6 , VOL. 87$]$ from which has sprung so many of our great men of science, including Hamilton, Stokes, and Kelvin, but which, through economic and political causes, is now fast disappearing. He came from strong stoclis on both sides, which have provided an unusually large number who have made their mark, including four Fellows of the Royal Society.

$\mathrm{He}$ was educated at Trinity College, Dublin, taking high place in his examinations. He was anxious to devote his life to collegiate work, and sat for the fellowship examination, the entrance in Trinity College to this, but, as in many other cases, his brilliant intellect was lost to his university through the unfortunate working of an examination system, now happily to be abolished.

For many years he held the post of secretary to the Queen's University of Ireland, a position affording him small leisure for pursuing his scientific researches. To his official duties he gave a wholehearted service. This involved much organisation of the scattered colleges which constituted that university, and it was with unfeigned regret he saw the work of these years abandoned on its dissolution.

All who came in contact with Johnstone Stoney were impressed with his sincerity and devotion to all which makes for truth and righteousness. He was veritably a prophet as of olden time. Younger scientific men who have had the privilege of knowing him will not easily forget his kindliness and encouragement.

He died on July $\mathrm{r}$, after a prolonged illness, in his cighty-sixth year, at his residence at Notting Hill Gate, where he had.lived for some years.

F. T. T.

\section{NOTES.}

A NEW attempt is being made to work the alluvial goldfield in Helmsdale, in eastern Sutherland. The existence of gold there has long been known, and some of the gold of the ancient ornaments found in north-eastern Scotland may have come from that district. The first modern attempt to work the field was in 1869 , when gold was obtained in the Kildonan and Suisgill Burns, two tributaries of the Ullie, the main stream of Helmsdale. Royalty was paid on about 3000 . of gold, but the amount obtained is said to have been considerably higher. The largest nugget was found in the Kildonan Burr, and weighed two ounces. The richest alluvial deposits were in the Suisgill Burn, a higher tributary of the Ullie. This burn flows over mica schists belonging to the Moine system, which have been invaded by granite dykes. The existence of gold in this granite was recorded by Bryce in 1870 . The workings were stopped at the end of 1869 owing to damage done to the fishing and the farmers. A serious effort to reopen the field is now being made by the Duke of Sutherland. Gold is being obtained, but whether it occurs in paying quantities has still to be proved.

Dr. H. N. Dickson, president of the Royal Meteorological Society, in a letter to The Times of Thursday, July 6 , raises the question of increasing the utility of the daily forecasts of weather issued by the Meteorological Office by more effective distribution. His letter suggests the general restoration of the afternoon service of weather forecasts, which is now only operative in the summer months. "Presumably these could be issued all the year round, and they could easily reach the general public before the arrangements for the next day's work were finally completed, provided proper facilities for distribution were given." The history of the public announcement of weather forecasts in this country includes some interesting 